\title{
Correlations Between rCBF and Symptoms in Two Independent Cohorts of Drug-Free Patients with Schizophrenia
}

\author{
Adrienne C Lahti*,', Martin A Weiler', Henry H Holcomb', Carol A Tamminga², William T Carpenter Jr' \\ and Robert McMahon' \\ 'Maryland Psychiatric Research Center, University of Maryland School of Medicine, Baltimore, MD, USA; '2 Department of Psychiatry, \\ UT Southwestern Medical Center, Dallas, TX, USA
}

\begin{abstract}
We report on the correlations between whole brain rCBF and the positive and negative symptoms of schizophrenia in two cohorts of patients who were scanned while free of antipsychotic medication. We hypothesized that positive symptoms would correlate with rCBF in limbic and paralimbic regions, and that negative symptoms would correlate with rCBF in frontal and parietal regions. Both cohorts of patients with schizophrenia (Cohort I: $n=32$; Cohort 2: $n=23$ ) were scanned using PET with $\mathrm{H}_{2}^{15} \mathrm{O}$ while free of antipsychotic medication for an average of 21 and 15 days, respectively. Both groups were scanned during a resting state. Using SPM99, we conducted pixel by pixel linear regression analyses between BPRS scores and whole brain rCBF. As hypothesized, positive symptoms correlated with $\mathrm{rCBF}$ in the anterior cingulate cortex (ACC) in a positive direction and with the hippocampus/parahippocampus in a negative direction in both patient groups. When the positive symptoms were further divided into disorganization and hallucination/delusion scores, similar positive correlations with $A C C$ and negative correlations with hippocampus rCBF were found. In both cohorts, the disorganization scores correlated positively with rCBF in Broca's area. As expected, negative symptoms correlated inversely with rCBF in frontal and parietal regions. This study provides evidence that limbic dysfunction may underlie the production of positive symptoms. It suggests that abnormal function of Broca's area may add a specific language-related dimension to positive symptoms. This study also provides further support for an independent neurobiological substrate of negative symptoms distinct from positive symptoms. The involvement of both frontal and parietal regions is implicated in the pathophysiology of negative symptoms.
\end{abstract}

Neuropsychopharmacology (2006) 3 I, 22 I-230. doi: I0.1038/sj.npp. I 300837; published online 3 August 2005

Keywords: Schizophrenia; PET; rCBF; ACC; hippocampus; psychosis

\section{INTRODUCTION}

From the start, researchers have been fascinated with the possibility of unraveling the anatomical underpinnings of schizophrenia symptoms. The availability of imaging techniques allowed the pursuit of this dream. Although more than 20 years have elapsed since the first imaging study was published, a clear understanding of the neural correlates of symptoms is still lacking.

Factor analysis has consistently demonstrated that the symptoms of schizophrenia fall into at least three independent factors: a negative factor comprising of poverty of

\footnotetext{
*Correspondence: Dr AC Lahti, Maryland Psychiatric Research Center, University of Maryland School of Medicine, PO Box 21247 , Baltimore, MD 21228, USA, Tel: + I 410402 6842, Fax: + I 4104026858 , E-mail: alahti@mprc.umaryland.edu

Received 12 December 2004; revised 5 May 2005; accepted II May 2005

Online publication: 21 June 2005 at http://www.acnp.org/citations/ Npp062 105040586/default.pdf
}

speech, affect, and movement, a reality distortion factor comprising of delusions and hallucinations and a disorganized factor comprising of thought disorder and inappropriate affect. Antipsychotic medication does not affect this factor composition, as it is found in drug-free and medicated patients alike (Lahti et al, 1998). In a landmark study, Liddle (Liddle et al, 1992) demonstrated that each of the three syndrome scores was associated with a specific pattern of perfusion in paralimbic, associative cortex, and subcortical nuclei. Other studies followed that confirmed the association between these factors and unique perfusion patterns (Ebmeier et al, 1993; Kaplan et al, 1993; Siegel Jr et al, 1993; Kawasaki et al, 1996; Schroder et al, 1996; Min et al, 1999; Tamminga et al, 1992). Differences between metabolic patterns were observed as well between three different subtypes of schizophrenia: negative, paranoid, and Schneiderian (Gur et al, 1995). A common theme that has emerged from these studies in spite of differences in patients' medication status, imaging methods, and analysis is a link between limbic regions, and positive symptoms 
(Ebmeier et al, 1993; Kawasaki et al, 1996; Klemm et al, 1996; Schroder et al, 1996; Min et al, 1999) or severity of illness (Friston et al, 1992).

Many studies to-date have focused on isolating the neural substrate of hallucinations, especially auditory hallucinations. Auditory hallucinations are one of the most frequently reported symptoms and one that patients with schizophrenia can usually isolate and characterize. Imaging studies first adopted a categorical approach to the study of hallucinations, dichotomizing patients on the basis of their presence or absence (see in Weiss and Heckers, 1999 for review). These studies, as well as correlational studies, can be construed as identifying patterns of brain activity that may give rise to the production of symptoms or, as Weiss put it, trait studies. With the advancement of imaging techniques, research was aimed at capturing hallucination state. Specifically, studies attempted to image, in the same person, periods when they were actively hallucinating and when they were not (McGuire et al, 1993; Silbersweig et al, 1995; Shergill et al, 2000; Woodruff et al, 1995). Other investigators sought to evaluate neocortical perfusion changes in response to active hallucination. In general, these studies have identified sensory and association cortical activity specific to the modality of the hallucination in addition to activation of limbic areas (Musalek et al, 1988, 1989; Walter et al, 1990; Cleghorn et al, 1992; McGuire et al, 1993; Silbersweig et al, 1995; Lennox et al, 1999; Dierks et al, 1999; Shergill et al, 2000; Suzuki et al, 1993). Other researchers pursed isolating the neural correlates of thought disorganization first in a PET (McGuire et al, 1998) followed by a fMRI (Kircher et al, 2001) study. In both studies, verbal disorganization scores correlated with middle temporal and caudate flow patterns; in addition, in the first study, they correlated with limbic and inferior frontal areas.

Unfortunately, many imaging studies that have attempted to identify a neural correlate of negative symptoms have not specifically investigated primary negative symptoms. The results of these studies were confounded by secondary negative symptoms, which can occur as a consequence of depression, paranoia, medication side effects, or other conditions. In contrast, imaging studies have carefully addressed this issue by comparing deficit and nondeficit schizophrenia. Results have consistently identified frontal and parietal hypometabolism in patients with deficit schizophrenia (Lahti et al, 2001; Heckers et al, 1999).

An important caveat in the majority of the aforementioned imaging studies is that they were performed with medicated patients. Several studies have found flow changes in response to antipsychotic medication in some of the regions that have been shown to be related to symptoms (Lahti et al, 2004, 2003). Thus, it is important to investigate the relationship between neuronal activity and symptom in nonmedicated patients.

In this study, we investigated the relationship between whole brain $\mathrm{rCBF}$ and the three main symptom factors, hallucination/delusion, disorganization, and negative symptoms, in two relatively large cohorts of patients who were scanned while free of antipsychotic medication.

We hypothesized that positive symptom scores would correlate with both ACC and hippocampus rCBF. Furthermore, we predicated that reality distortion (hallucination/ delusion) scores would correlate with hippocampal rCBF while disorganization scores would correlate with ACC rCBF. Finally, we hypothesized that negative symptom scores would correlate with frontal and parietal, but not with limbic, rCBF.

\section{MATERIALS AND METHODS}

\section{Volunteers}

We report on two groups of persons with schizophrenia who were enrolled in imaging studies. Both studies included the acquisition of a scan during a resting state while patients were free of all psychotropic medication. The two studies were distinguished by the acquisition of data on different PET cameras.

Data from the first study (Cohort 1: $n=32$ ) were acquired between 1992 and 1997 on the GE 4096 + PET camera while patients had been withdrawn from medication for an average of 21.7 days (range 6-90 days). Data from the second study (Cohort 2: $n=23$ ) were acquired between 1999 and 2003 on the GE Advance 3D camera while patients had been off medication for 2 weeks. Characteristics of patients in these two cohorts are presented in Table 1.

The methods to recruit patients and to taper patients off their medications were consistent across the three studies.

All volunteers with schizophrenia were otherwise healthy persons who were recruited from the Residential Research Unit of the Maryland Psychiatric Research Center in Baltimore, MD. Each underwent a Structured Clinical Interview for diagnosis at hospital admission. Two research psychiatrists reached a consensus diagnosis of schizophrenia based on the clinical interview plus all other sources of

Table I Demographics

\begin{tabular}{|c|c|c|c|c|c|c|c|c|c|c|}
\hline & Sex & Race & Age & $\begin{array}{c}\text { Deficit/ } \\
\text { nondeficit } \\
\text { syndrome }\end{array}$ & $\begin{array}{l}\text { Length of } \\
\text { illness } \\
\text { (years) }\end{array}$ & $\begin{array}{c}\text { BPRS } \\
\text { Total } \\
\text { scores }\end{array}$ & $\begin{array}{c}\text { BPRS } \\
\text { Psychosis } \\
\text { scores }\end{array}$ & $\begin{array}{l}\text { BPRS item } \\
4 \text { scores }\end{array}$ & $\begin{array}{l}\text { BPRS items } \\
12 \text { and } 15 \\
\text { scores }\end{array}$ & $\begin{array}{c}\text { BPRS } \\
\text { Withdrawal } \\
\text { scores }\end{array}$ \\
\hline \multirow[t]{2}{*}{ Cohort I } & $24 \mathrm{M} / 8 \mathrm{~F}$ & $19 \mathrm{C} / 8 \mathrm{AA} / 4 \mathrm{~A}$ & 35.2 & $10 / 22$ & 13.8 & 33.7 & 7.6 & 2 & 5.6 & 6.2 \\
\hline & & & \pm 9.4 & & \pm 8.5 & \pm 8.4 & \pm 3.4 & \pm 1.3 & \pm 2.9 & \pm 2.8 \\
\hline \multirow[t]{2}{*}{ Cohort 2} & $18 \mathrm{M} / 5 \mathrm{~F}$ & $7 \mathrm{C} / 6 \mathrm{AA}$ & 35.2 & $4 / 19$ & 12.7 & 33.2 & 6.6 & 2.4 & 4.1 & 6.5 \\
\hline & & & \pm 13.2 & & \pm 11.9 & \pm 7.0 & \pm 2.4 & \pm 1.6 & \pm 1.5 & \pm 3.4 \\
\hline
\end{tabular}

M, Male; F, Female; C, Caucasian; AA, African American; A, Asian. 
data utilizing DSM IV criteria. The diagnosis of deficit syndrome (primary negative symptoms) was made using the Schedule for the Deficit Syndrome (Kirkpatrick et al, 1989).

All schizophrenia volunteers were withdrawn from all medication prior to scanning. All other aspects of in-patient milieu treatment were continued during this project. Clinical monitoring was continuously performed and intervention (including study termination) was possible based on clinical judgement of adverse behavioral change requiring treatment. Symptoms of schizophrenia were assessed repeatedly at baseline and during the subsequent drug-free period utilizing the Brief Psychiatric Rating Scale (BPRS) (1-7 scale). In these analyses, we focused on six items, with a positive symptom (Psychosis) factor defined by measures of conceptual disorganization, hallucinations and delusions, and a negative symptom (Withdrawal) factor defined by emotional withdrawal, motor retardation and blunted affect. The BPRS Psychosis scores were further subdivided into disorganization (BPRS item 4) and hallucination/delusion (BPRS item 12 and 15) scores. For Cohort 1, correlations between negative symptoms and rCBF were also obtained for both the deficit and the nondeficit patients. This analysis was not obtained for the second cohort because of the small number of deficit patients.

\section{Informed Consent}

Schizophrenia volunteers were fully informed about the nature of the protocol during an educational process spanning several days. After being informed, each gave consent. Only patients who were competent and clinically judged to be capable of understanding and appreciating the risks involved in this study were selected to participate. Separate people including both the Principal Investigator and noninvestigator clinicians presented the nature of the protocol to the volunteers on several occasions and assessed their willingness to be involved. Family members or caregivers were involved in the information process when available. Starting in 1998, new procedures were put in place, which further increased patient safeguards. A patient's rights advocate met with every potential patient upon admission and an ombudsman monitored patients through research participation. Prior to signing consent, each patient passed an Evaluation to Sign Consent Form Test, a form probing the patient's understanding of some important aspects of the protocol.

All projects were approved by the University of Maryland IRB.

\section{PET Imaging}

For both studies, the bolus $\mathrm{H}_{2}^{15} \mathrm{O}$ method (Raichle et al, 1983) was used without arterial blood sampling. For Cohort 1, PET scans were obtained using the General Electric $4096+$ system, which produced 15 brain image slices at an intrinsic resolution of $6.1 \mathrm{~mm}$ in each dimension. Approximately $62 \mathrm{mCi} \mathrm{H}_{2}^{15} \mathrm{O}$ was administered with each scan. Cohort 2 utilizes the GE Advance 3D that produced 30 slices with an average transaxial resolution of $5.0 \mathrm{~mm}$ full-width at half-maximum (FWHM) and an average axial resolution of
6.0 mm FWHM. Approximately $12 \mathrm{mCi} \mathrm{H}_{2}^{15} \mathrm{O}$ was administered with each scan.

\section{Image Analysis}

The quantitative PET blood flow images were analyzed with statistical parametric mapping (SPM 99) routines (Friston et al, 1996). The scans from each subject were realigned using the first as a reference. Following realignment all images were transformed into a standard anatomical space (Montreal Neurological Institute Atlas). Prior to generating the $\operatorname{SPM}_{(\mathrm{z})}$ map the data were smoothed using a $12-\mathrm{mm}$ Gaussian kernel. Using SPM 99, we generated pixel by pixel linear regression between BPRS scores and whole brain rCBF. For the ACC and the hippocampus, the primary criteria for statistical significance was set at $p=0.001$, uncorrected, assuming a cluster of at least 50 and 30 suprathreshold voxels, respectively. For all other brain regions, only clusters of connected voxels above a threshold $(Z=2.5)$ were tested for significance by means of spatial extent statistic which was set at $p=0.05$, after correcting for multiple comparisons (Friston et al, 1996). To calculate the coefficient of correlation between rCBF in significant clusters identified in the SPM analysis and symptoms' scores, $\mathrm{rCBF}$ values were sampled in the maxima of these clusters using a $3 \times 3 \times 3\left(6 \times 6 \times 2 \mathrm{~mm}^{3}\right)$ pixel ROI.

\section{RESULTS}

Correlations found between BPRS symptom scores and rCBF are summarized in Tables 2 and 3 for Cohort 1 and Table 4 for Cohort 2.

\section{Cohort 1}

BPRS Total scores were correlated positively with $\mathrm{rCBF}$ in rostral ACC (rACC) and negatively correlated with rCBF in the left occipital cortex, the left inferior parietal cortex and the left hippocampus. Correlation plots between BPRS Total scores and $\mathrm{rCBF}$ in rACC and left hippocampus are shown in Figure 1.

BPRS Psychosis scores showed a trend for positive correlation with $\mathrm{rCBF}$ in rACC and negative correlation with $\mathrm{rCBF}$ in the left hippocampus. When the BPRS Psychosis scores were further subdivided into disorganization and hallucination/delusion scores, disorganization scores positively (and significantly) correlated with the left inferior frontal cortex (Figure 3) and, at a trend level, with the $\mathrm{rACC} \mathrm{rCBF}$, while hallucinations/delusions scores were negatively (and significantly) correlated with $\mathrm{rCBF}$ in the left hippocampus/parahippocampus.

BPRS Withdrawal scores were negatively correlated with $\mathrm{rCBF}$ in the occipital cortex, bilaterally, and in the left inferior parietal cortex. In deficit syndrome patients, BPRS Withdrawal scores were negatively correlated with $\mathrm{rCBF}$ in the right occipital cortex, the right inferior parietal cortex and the left middle frontal cortex. In nondeficit syndrome patients, the Withdrawal scores were negatively correlated with the right inferior parietal cortex, the middle frontal cortex, bilaterally, and the left motor cortex (Figure 4). 
Table 2 Correlation between BPRS Scores and rCBF: Cohort I $(n=32)$

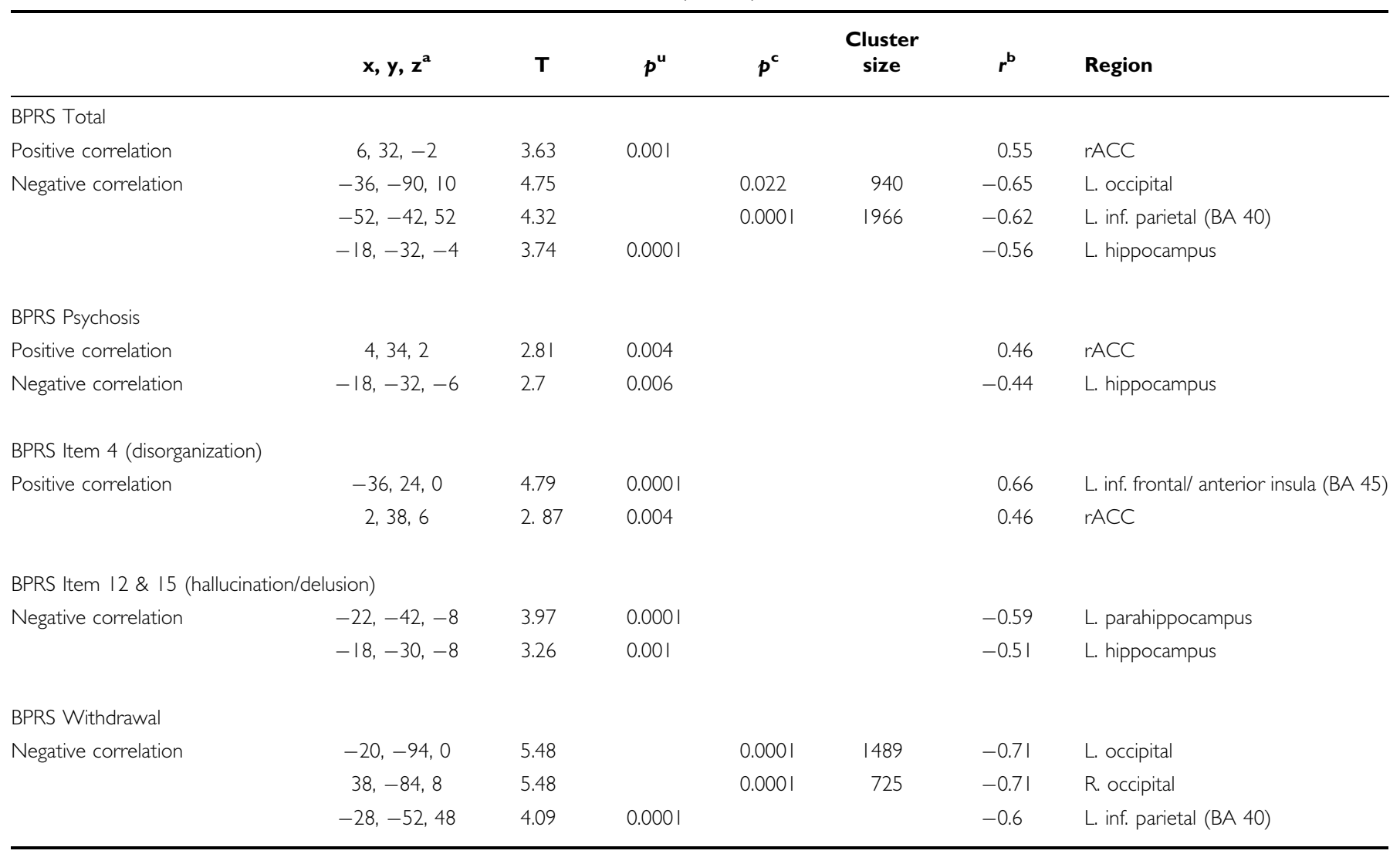

Montreal Neurological Institute Coordinates; $p^{\mathrm{u}}: p<0.001$, uncorrected; $p^{c}: p<0.05$, after correcting for multiple comparisons; $r^{b}$; coefficient of correlation between BPRS scores and rCBF values extracted around the center of significant maxima identified in the SPM analysis.

Table 3 Correlations between BPRS Withdrawal (Negative Correlation) Scores and rCBF in Deficit and Nondeficit Patients: Cohort I

\begin{tabular}{|c|c|c|c|c|c|c|}
\hline$x, y, z^{a}$ & $\mathbf{T}$ & $p^{u}$ & $p^{c}$ & Cluster size & $r^{b}$ & Region \\
\hline \multicolumn{7}{|c|}{ Deficit patients $(n=10)$} \\
\hline $18,-86,32$ & 6.12 & & 0.011 & 671 & -0.9 & R. occipital \\
\hline $60,-44,24$ & 5.17 & 0.0001 & & & -0.88 & R. inf. parietal (BA 40) \\
\hline$-22,18,38$ & 4.54 & 0.001 & & & -0.84 & L. middle frontal (BA 8/9) \\
\hline$-58,-24,48$ & 5.18 & & 0.044 & 181 & -0.75 & L. motor C. \\
\hline$-34,34,38$ & 4.67 & & 0.026 & 214 & $-0.7 \mid$ & L. middle frontal C. \\
\hline$-46,30,24$ & 4.27 & & & & & $(B A 9 \& 46)$ \\
\hline $42,20,26$ & 4.19 & 0.0001 & & & -0.68 & R. middle frontal (BA 46) \\
\hline $58,-26,28$ & 3.94 & 0.0001 & & & -0.65 & R. inf. parietal C. (BA 40) \\
\hline
\end{tabular}

a Montreal Neurological Institute Coordinates; $p^{\mathrm{u}}: p<0.00$ I, uncorrected; $p^{c}: p<0.05$, after correcting for multiple comparisons; $r^{\mathrm{b}}$; coefficient of correlation between BPRS scores and rCBF values extracted around the center of significant maxima identified in the SPM analysis.

\section{Cohort 2}

BPRS Total scores were correlated positively with rACC and negatively correlated with $\mathrm{rCBF}$ in the left inferior parietal cortex, the left middle frontal cortex and the left hippocampus. Correlation plots between BPRS Total scores and rCBF in rACC and left hippocampus are shown in Figure 1.
BPRS Psychosis scores were positively correlated with $\mathrm{rCBF}$ in both the rACC and the caudal ACC (cACC) and, at a trend level, negatively correlated with $\mathrm{rCBF}$ in the left hippoccampus (Figure 2). When the BPRS Psychosis scores were further subdivided into disorganization and hallucination/delusion scores, disorganization scores were positively correlated with $\mathrm{rCBF}$ in the left inferior frontal cortex (Figure 3) 
Table 4 Correlations between BPRS Scores and rCBF: Cohort $2(n=23)$

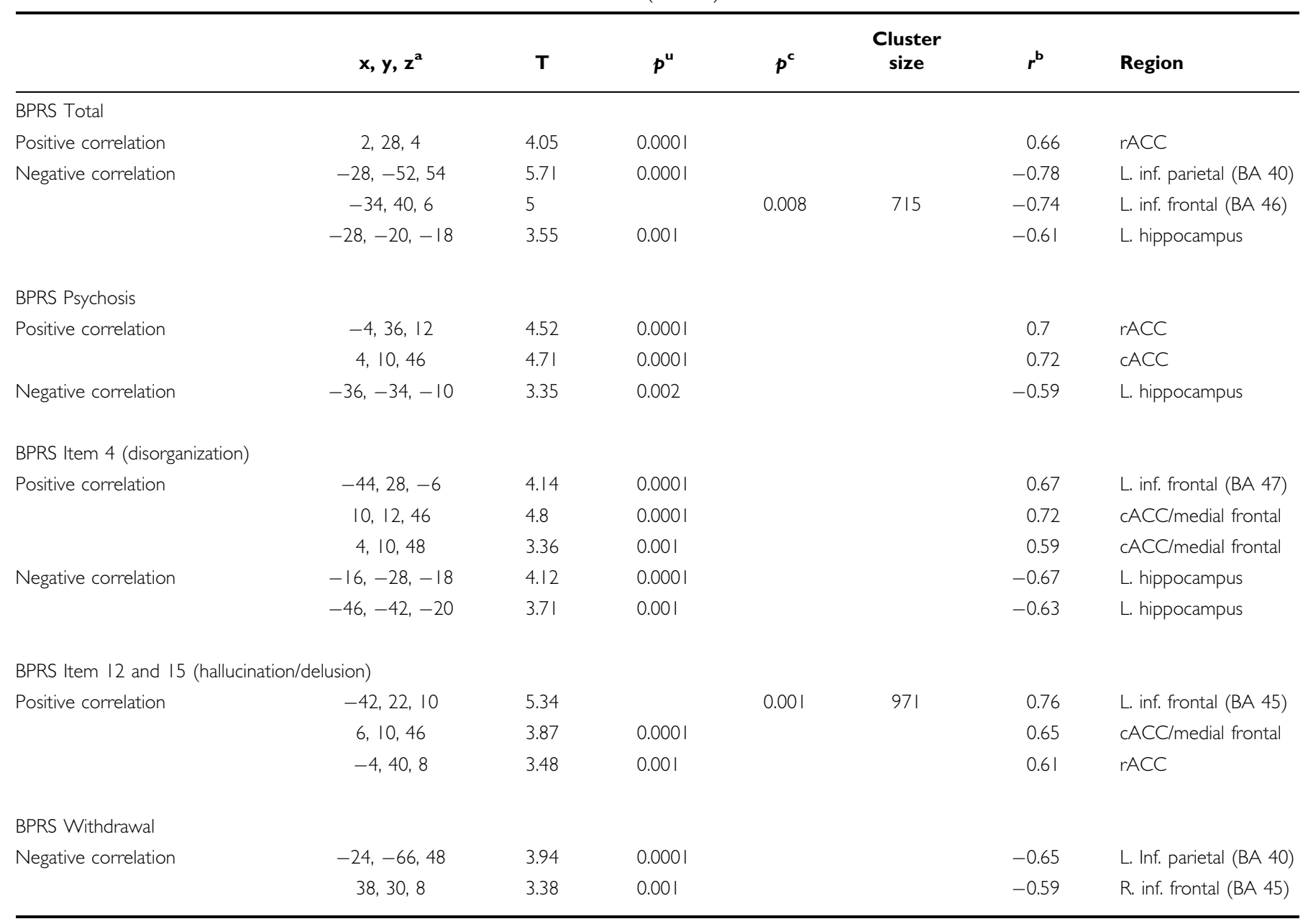

a Montreal Neurological Institute Coordinates; $p^{\mathrm{u}}: p<0.00$ I, uncorrected; $p^{c}: p<0.05$, after correcting for multiple comparisons; $r^{b}$; coefficient of correlation between BPRS scores and $r$ CBF values extracted around the center of significant maxima identified in the SPM analysis.

and in the cACC/medial frontal cortex and negatively correlated with $\mathrm{rCBF}$ in the left hippocampus. Hallucination/ delusion scores were positively correlated with $\mathrm{rCBF}$ in both the $r$ and $c$ ACC and in the left inferior frontal cortex.

BPRS Withdrawal scores were negatively correlated with rCBF in the left inferior parietal cortex and, at a trend level, in the right inferior frontal cortex (Figure 4). A deficit/ nondeficit analysis was not performed based on the small $N$ for the deficit subgroup.

In order to anatomically better define the region of the ACC and hippocampus associated with psychosis, we generated a correlation analysis between the BPRS Psychosis scores of all patients included in the two cohorts $(n=55)$ and whole brain rCBF. This analysis confirmed a significant positive correlation between $\mathrm{rCBF}$ in the rostral $\operatorname{ACC}(-2,36,10)$ and a negative correlation (at a trend level) between $\mathrm{rCBF}$ in the left hippocampus $(-28,-22,-12)$ and BPRS Psychosis scores.

\section{DISCUSSION}

In a 'trait' study of two independent and relatively large groups of drug-free patients with schizophrenia, we have identified brain regions where $\mathrm{rCBF}$ patterns during a resting state correlated with both the positive (further delineated into reality distortion and disorganization) and the negative symptoms of schizophrenia.

As hypothesized, both patient cohorts showed rCBF in the ACC to be positively related and rCBF in the hippocampal/ parahippocampal regions to be negatively correlated with positive symptoms. Positive correlations with ACC and negative correlations with hippocampus $\mathrm{rCBF}$ were found both with the reality distortion and disorganization items, suggesting that these areas may make a central contribution to severity of psychosis, irrespective of the subsyndroms. The disorganization item consistently correlated with $\mathrm{rCBF}$ in left inferior frontal cortex. These data inform us on brain structures whose pathophysiology has the potential to give rise to positive symptoms. These data complement studies evaluating brain activity associated with the hallucinatory or disorganized state. Consistent with our previous findings, negative symptoms correlated with frontal and parietal rCBF, but not with ACC or hippocampal rCBF, confirming that negative symptoms have a differential neuroanatomic substrate from positive psychotic symptoms. However, the negative symptom correlations were similar in the deficit and nondeficit schizophrenia subgroups, suggesting that the primary/secondary negative symptom distinction is not 


\section{Correlations rCBF/BPRS Total scores}

Cohort 1 (n=32)

Cohort $2(n=23)$

Positive correlation in ACC
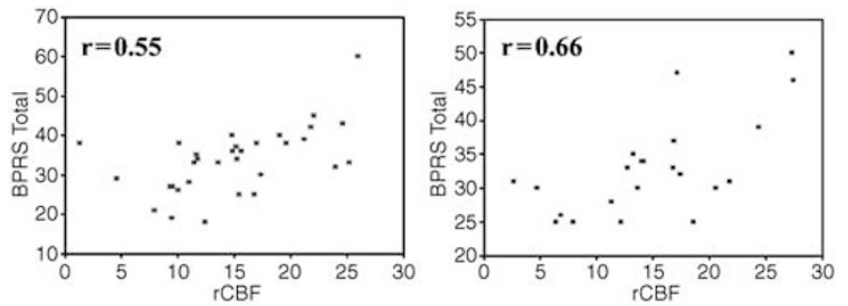

Negative correlation in hippocampus
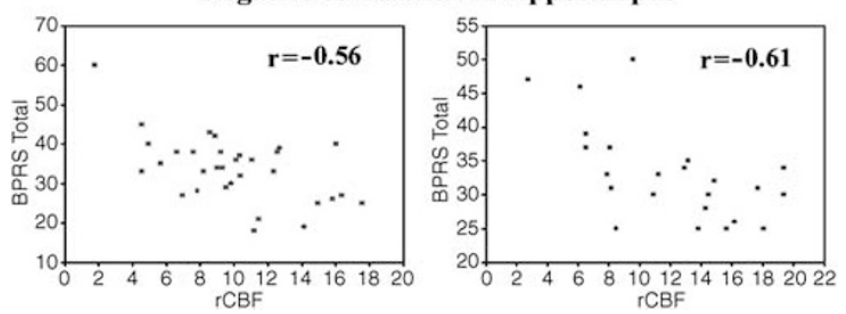

Figure I Statistical parametric mapping (SPM99) was used to generate pixel by pixel linear regression between BPRS Total scores and whole brain rCBF in two cohorts of drug-free patients with schizophrenia scanned during a resting state. In regions where significant correlations were identified, rCBF values were extracted and plotted against BPRS Total scores. Plots for Cohort I $(n=32)$ are for Cohort $2(n=23)$ are shown on the left and right panels, respectively. In both cohorts, positive correlations with ACC (right and left upper panels) and negative correlations with hippocampus (right and left lower panels) rCBF were identified.

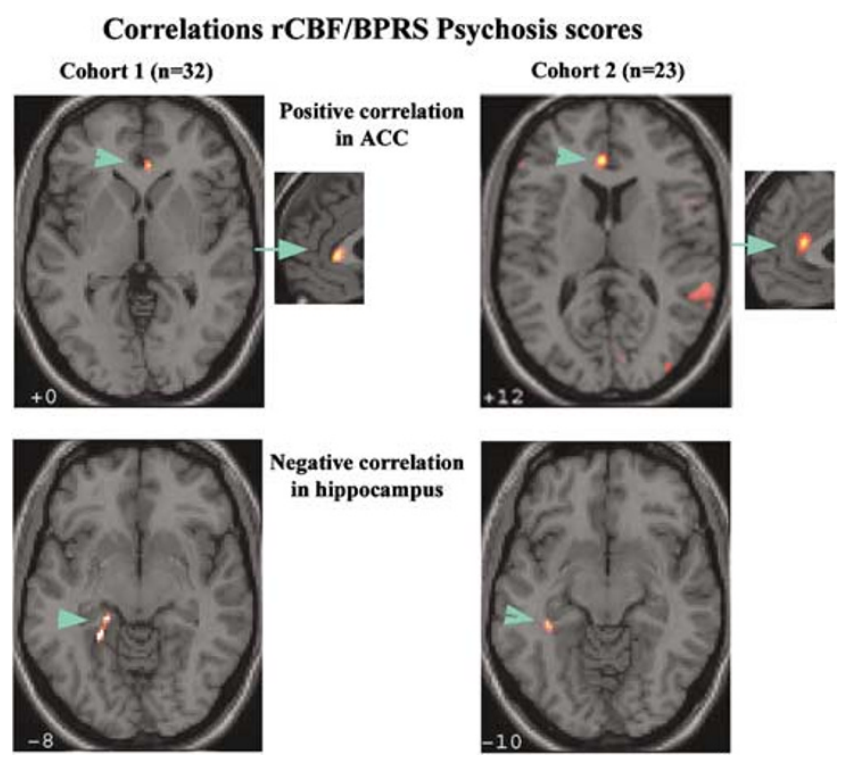

Figure 2 For both cohorts (Cohort I, left panels; Cohort 2, right panels), positive and negative correlations between rCBF and BPRS Psychosis score were identified in the ACC and the hippocampus, respectively. Correlations in these regions were significant for Cohort 2 and at a trend level for Cohort I. The ACC/rCBF correlations are displayed in both axial and sagittal planes. The display threshold for voxel was set at $p<0.01$.

critical. These anatomic areas have previously discriminated between these two schizophrenia subgroups when the rCBF was measured during task performance (Lahti et al, 2001)and at rest with PET glucose metabolic activity (Tamminga et al, 1992).

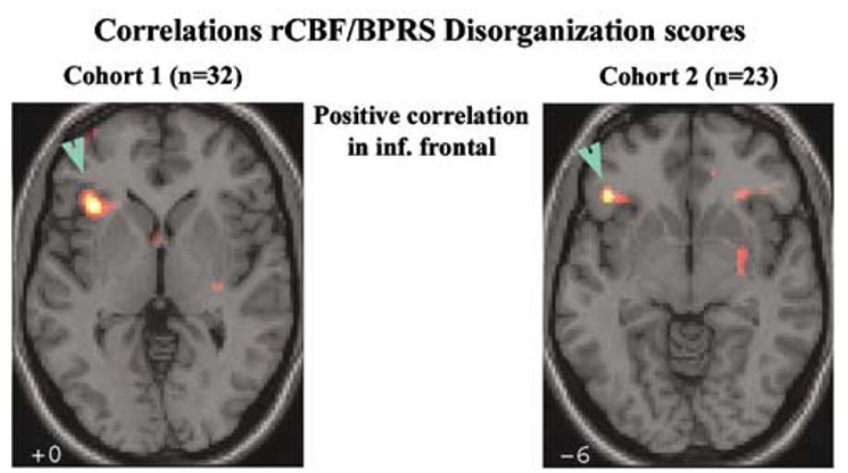

Figure 3 For both cohorts (Cohort I, left panel; Cohort 2, right panel), a positive correlation between $\mathrm{rCBF}$ and the disorganization item of the BPRS (item \# 4) was identified in the left inferior frontal cortex. The display threshold for voxel was set at $p<0.01$.

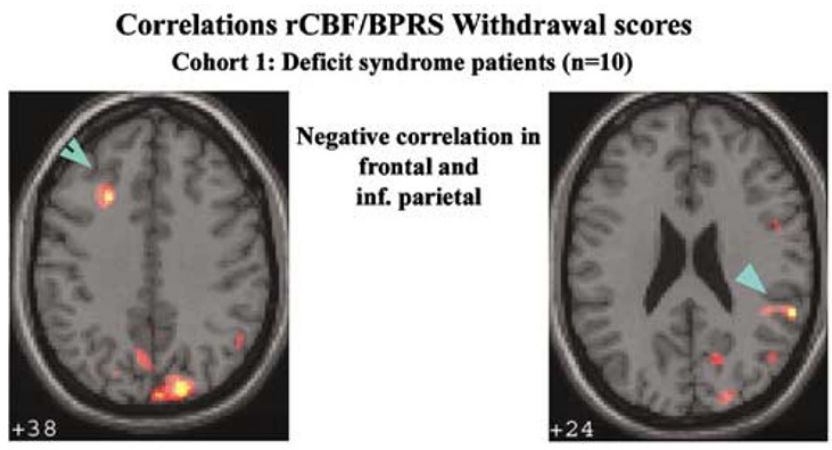

Cohort 1: Nondeficit syndrome patients $(\mathrm{n}=\mathbf{2 2})$
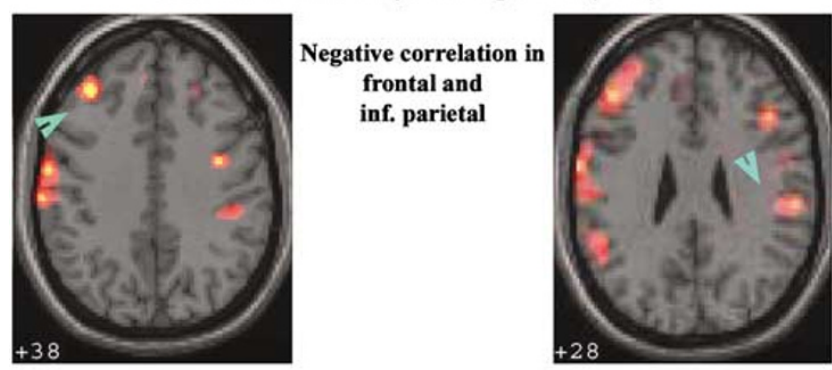

Cohort $2(n=23)$
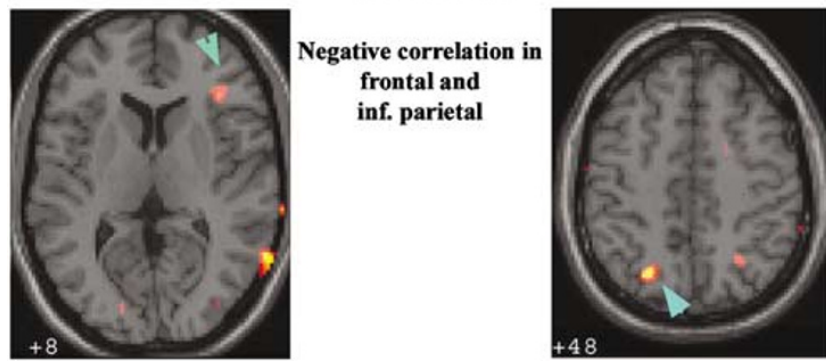

Figure 4 For both deficit and nondeficit patients of Cohort I (deficit patients, superior panels; nondeficit patients, middle panel), a negative correlation between rCBF and the BPRS withdrawal scores was identified in the left frontal cortex (left panels) and in the right inferior parietal cortex (right panels). For Cohort 2 (inferior panels), there was also a negative correlation between $\mathrm{rCBF}$ and negative symptoms in the right inferior frontal cortex (left panel) and the left inferior parietal cortex (right panel). The display threshold for voxel was set at $p<0.01$. 
This study adds to a growing imaging literature, which has identified alteration in limbic cortex activity associated with the presence of positive symptomatology. In drug-free patients in a resting state, a positive correlation between hallucination scores and relative metabolism was identified in the ACC (Cleghorn et al, 1992). In medicated patients, a positive correlation between thought disorganization and resting ACC rCBF was also identified (Liddle et al, 1992). Hypnotizable persons with an ability to hallucinate under hypnosis showed rostral ACC activation during auditory hallucination (Szechtman et al, 1998). Psychosis exacerbation with the NMDA antagonist, ketamine, is accompanied by increases in ACC $\mathrm{CCBF}$ and the induced behavioral changes correlate with ACC rCBF (Lahti et al, 1999). While most studies have reported a positive correlation between ACC $\mathrm{rCBF}$ and positive symptoms, when it comes to the medial temporal region, both positive (Liddle et al, 1992; McGuire et al, 1998) and negative (Friston et al, 1992; Ebmeier et al, 1993; Kawasaki et al, 1996; Min et al, 1999) correlations have been reported. These conflicting results may be attributable to medication status, imaging methods, and analyses. In fact, positive correlations have been identified in medicated patients (Liddle et al, 1992; McGuire et al, 1998) and negative correlation in medication free (Ebmeier et al, 1993; Schroder et al, 1996) or drug naïve (Min et al, 1999) with one exception (Kawasaki et al, 1996). Interestingly, the specific medial temporal locations are exquisitely close across studies despite the differing relationship direction between $\mathrm{rCBF}$ and positive symptoms. State studies aimed at capturing the hallucinatory state have also identified both the ACC and hippocampal/parahippocampal activation, usually in addition to the sensory and association cortex specific to the modality of the hallucination (Silbersweig et al, 1995; Shergill et al, 2000).

Thus, there is adequate background support to implicate either or both regions in relation with positive symptoms. The limbic regions revealed in these analyses have been consistently shown to be abnormal in schizophrenia through a myriad of studies, and therefore are believed to be intrinsically involved in the pathophysiology of schizophrenia.

\section{ACC: Normal Function and Abnormalities in Schizophrenia}

Human imaging studies and meta-analysis of human imaging have identified the subcallosal ACC as being involved in emotional processing (Bush et al, 2000) or internal states (Greicius et al, 2003), and the cACC as being involved in mediating attention and executive functions. Supporting this functional specialization, the 'affective' ACC subdivision has connections to limbic and paralimbic areas whereas the 'cognitive' subdivision is interconnected with the dosolateral prefrontal cortex, parietal cortex, premotor, and supplementary motor areas (Vogt et al, 1992; Devinsky et al, 1995). The rostral ACC, located between these two subdivisions, has been thought to play an important role in the integration of functions sustained by these regions (Mayberg et al, 2000). Postmortem (see for review in Harrison 1999; Benes et al, 2000), in vivo MRI (see for review in Shenton et al, 2001) and functional imaging studies (Carter et al, 1997; Carter et al, 2001; Nordahl et al, 1996; Holcomb et al, 2000; Tamminga et al, 1992) point to abnormal function of the ACC in schizophrenia. Imaging (Carter et al, 1997, 2001) and electrophysiology studies (Kopp and Rist, 1999; Alain et al, 2002; Mathalon et al, 2002) have provided evidence of the impairment in cingulate function during error or conflict monitoring in schizophrenia. Further, two of these studies (Kopp and Rist 1999; Mathalon et al, 2002) have reported a link between this abnormality and the presence of positive symptoms.

\section{Hippocampal/Parahippocampal Regions: Normal Function and Abnormalities in Schizophrenia}

Studies of humans with lesions in the hippocampal and parahippocampal regions have established that damage to these areas causes impairment in the ability to form new declarative memories. Imaging studies have also greatly contributed to define the intricacy of hippocampal function and declarative memory. Recent lesion and imaging studies have suggested that hippocampal and posterior parahippocampal regions subserve awareness and source recollection, while the anterior parahippocampal region subserves familiarity-based recognition (Ranganath et al, 2004). Converging lines of evidence, including postmortem (see for review in Harrison, 1999), in vivo MRI (see for review in Shenton et al, 2001), neuropsychological (Saykin et al, 1991), and functional imaging studies, point to abnormal medial temporal function in schizophrenia. Functional imaging studies have shown abnormalities of these regions during a resting state, (Nordahl et al, 1996; Heckers et al, 1998; Medoff et al, 2001; Tamminga et al, 1992) and abnormal modulation during such tasks as novel picture encoding (Zorrilla et al, 2002), episodic memory encoding (Ragland et al, 2001; Jessen et al, 2003) and retrieval (Heckers et al, 1998; Ragland et al, 2001; Jessen et al, 2003; Weiss et al, 2003).

These regions that appear to predispose individuals to the expression of positive symptoms, are connected through known limbic circuits. The ACC projects to the entorhinal cortex, which reaches the hippocampus via polysynaptic relays in the parahippocampal gyrus and subiculum (Van Hoesen, 1982; Insausti et al, 1987). Efferent signals from the hippocampus utilize two major neuronal pathways (Rolls, 2000), one that projects back to the entorhinal cortex and to the cortical areas, and the other that projects to the ACC/ medial frontal cortex via the mammillary bodies and the anterior thalamus. Based on the knowledge that brain electrical stimulation (Penfield and Perot, 1963) (Gloor, 1990) and pharmacologic changes (Lahti et al, 1995) can induce schizophrenia-like positive symptoms, we hypothesize that transient changes in the electrophysiological and/or neurochemical balance in these regions might trigger a cascade of events leading to the experience of positive symptom.

Within this framework, the complex symptom manifestations that are particular to each patient with schizophrenia could stem from a unique pattern of limbic dysfunction. For example, dysfunctional cACC could result in defective error monitoring leading to misattribution of thoughts and action, while malfunction in rostral ACC could lead to abnormal emotional attribution to internal or external events. As a result of disrupted hippocampus function, abnormal binding of semantic or contextual information to 
material to be remembered could lead to the formation of inappropriate memories.

Both cohorts evidenced a positive correlation between the left inferior frontal cortex (Broca's area) and the disorganization item. As a result of its relationship with receptive language, several researchers have hypothesized a connection between Broca's area, inner speech and auditory hallucination. In previous studies, Broca's area was activated during active hallucination (McGuire et al, 1993) and metabolism of the right equivalent of Broca's area was negatively correlated with the disorganization dimension (Liddle et al, 1992). Together these data suggest that abnormal function of this area is a specific language-related dimension of positive symptoms.

As hypothesized, inferior frontal, and inferior parietal regions were inversely correlated with negative symptoms. Functional imaging studies seeking regional associations between brain metabolism and negative symptoms have been typically based on correlation (Wolkin et al, 1992; Sabri et al, 1997), factor analysis (Liddle et al, 1992; Kaplan et al, 1993; Yuasa et al, 1995; Kawasaki et al, 1996; Schroder et al, 1996) or categorical (ie deficit vs nondeficit schizophrenia) (Andreasen et al, 1992; Heckers et al, 1999; Lahti et al, 2001; Potkin et al, 2002; Tamminga et al, 1992) analyses. The majority of these studies have reported hypometabolism in frontal cortex during rest (Liddle et al, 1992; Wolkin et al, 1992; Kaplan et al, 1993; Yuasa et al, 1995; Sabri et al, 1997) and task-activated states (Andreasen et al, 1992; Schroder et al, 1996; Potkin et al, 2002) in association with negative symptoms. In addition, three of these studies also showed reduced functional recruitment of the inferior parietal cortex in deficit compared to nondeficit subjects either at rest (Tamminga et al, 1992) or during task performance (Lahti et al, 2001; Heckers et al, 1999).

In contrast to positive symptoms, which fluctuate with time and improve with antipsychotic medications (APD), primary negative symptoms typically remained stable over time and do not change with APDs. We speculate that primary deficit symptoms are generated by functional failures of neuronal populations in parietal and frontal regions. In vivo functional imaging studies implicate the frontal cortex in cognitive processes such as working memory, episodic retrieval, semantic processing and attention. Likewise, the inferior parietal cortex is activated by tasks requiring spatial attention and spatial processing. Supporting functional impairment of these regions, Buchanan et al (1997) have reported that subjects with deficit symptoms performed worse in some of these cognitive functions than nondeficit patients.

There are some limitations to this study that should be acknowledged. Our study tested the hypothesis that limbic dysfunction underlies the production of positive symptoms. However, it is likely that other brain regions are involved as well. For example, a positive correlation between positive symptoms and superior temporal metabolism was identified in a group of 42 either drug-naïve or drug-free patients (Gur et al, 1995). Also, a 2-3 week withdrawal is probably not long enough to allow medication-induced brain changes to fully revert to a 'baseline' condition. Thus, we cannot claim that the rCBF patterns after drug washout represent a truly drug-free condition.
This study is unique in that it investigated the relationship between schizophrenia symptom factors and $\mathrm{rCBF}$ in two large groups of antipsychotic-withdrawn patients. In summary, our results provide consistent evidence that limbic dysfunction may underlie positive symptoms and frontal-parietal dysfunction may underlie negative symptoms. This study provides further support for the independent pathophysiology of negative and positive symptoms. This study provides a framework to propose working hypotheses about the pathophysiology of symptoms.

\section{ACKNOWLEDGEMENTS}

The National Institute of Mental Health Grants RO1MH57971 (ACL), P30-MH40279 (IRC), RO1MH49667 (CAT) and the William K Warren Medical Research Institute supported this work. We thank all to the volunteers with schizophrenia who took part in this project; Dale Warfel and the nursing staff of the RRU of the Maryland Psychiatric Research Center for clinical care.

\section{REFERENCES}

Alain C, McNeely HE, He Y, Christensen BK, West R (2002). Neurophysiological evidence of error-monitoring deficits in patients with schizophrenia. Cereb Cortex 12: 840-846.

Andreasen NC, Rezai K, Alliger RJ, Swayze II VW, Flaum M, Kirchner $P$ et al (1992). Hypofrontality in neuroleptic-naive patients and in patients with chronic schizophrenia. Assessment with xenon 133 single- photon emission computed tomography and the Tower of London. Arch Gen Psychiatr 49: 943-958.

Benes FM, Todtenkopf MS, Logiotatos P, Williams M (2000). Glutamate decarboxylase(65)-immunoreactive terminals in cingulate and prefrontal cortices of schizophrenic and bipolar brain. J Chem Neuroanat 20: 259-269.

Buchanan RW, Strauss ME, Breier A, Kirkpatrick B, Carpenter WT (1997). Attentional impairments in deficit and nondeficit forms of schizophrenia. Am J Psychiatr 154: 363-370.

Bush G, Luu P, Posner MI (2000). Cognitive and emotional influences in anterior cingulate cortex. Trends Cogn Sci 4: 215-222.

Carter CS, MacDonald III AW, Ross LL, Stenger VA (2001). Anterior cingulate cortex activity and impaired self-monitoring of performance in patients with schizophrenia: an event-related fMRI study. Am J Psychiatr 158: 1423-1428.

Carter CS, Mintun M, Nichols T, Cohen JD (1997). Anterior cingulate gyrus dysfunction and selective attention deficits in schizophrenia: [15O]H2O PET study during single-trial Stroop task performance. Am J Psychiatr 154: 1670-1675.

Cleghorn JM, Franco S, Szechtman B, Kaplan RD, Szechtman H, Brown GM et al (1992). Toward a brain map of auditory hallucinations. Am J Psychiatry 149: 1062-1069.

Devinsky O, Morrell MJ, Vogt BA (1995). Contributions of anterior cingulate cortex to behaviour. Brain 118(Part 1): 279-306.

Dierks T, Linden DE, Jandl M, Formisano E, Goebel R, Lanfermann $\mathrm{H}$ et al (1999). Activation of Heschl's gyrus during auditory hallucinations. Neuron 22: 615-621.

Ebmeier KP, Blackwood DH, Murray C, Souza V, Walker M, Dougall N et al (1993). Single-photon emission computed tomography with $99 \mathrm{mTc}$-exametazime in unmedicated schizophrenic patients. Biol Psychiatry 33: 487-495.

Friston KJ, Holmes A, Poline JB, Price CJ, Frith CD (1996). Detecting activations in PET and fMRI: levels of inference and power. Neuroimage 4: 223-235. 
Friston KJ, Liddle PF, Frith CD, Hirsch SR, Frackowiak RS (1992). The left medial temporal region and schizophrenia. A PET study. Brain 115(Part 2): 367-382.

Gloor P (1990). Experiential phenomena of temporal lobe epilepsy. Facts and hypotheses. Brain 113(Part 6): 1673-1694.

Greicius MD, Krasnow B, Reiss AL, Menon V (2003). Functional connectivity in the resting brain: a network analysis of the default mode hypothesis. Proc Natl Acad Sci USA 100: 253-258.

Gur RE, Mozley PD, Resnick SM, Mozley LH, Shtasel DL, Gallacher $\mathrm{F}$ et al (1995). Resting cerebral glucose metabolism in firstepisode and previously treated patients with schizophrenia relates to clinical features. Arch Gen Psychiatr 52: 657-667.

Harrison PJ (1999). The neuropathology of schizophrenia. A critical review of the data and their interpretation. Brain 122(Part 4): 593-624.

Heckers S, Goff D, Schacter DL, Savage CR, Fischman AJ, Alpert NM et al (1999). Functional imaging of memory retrieval in deficit vs nondeficit schizophrenia. Arch Gen Psychiatr 56: 1117-1123.

Heckers S, Rauch SL, Goff D, Savage CR, Schacter DL, Fischman AJ et al (1998). Impaired recruitment of the hippocampus during conscious recollection in schizophrenia. Nat Neurosci 1: 318-323.

Holcomb HH, Lahti AC, Medoff DR, Weiler M, Dannals RF, Tamminga CA (2000). Brain activation patterns in schizophrenic and comparison volunteers during a matched-performance auditory recognition task. Am J Psychiatr 157: 1634-1645.

Insausti R, Amaral DG, Cowan WM (1987). The entorhinal cortex of the monkey: II. Cortical afferents. J Comp Neurol 264: 356-395.

Jessen F, Scheef L, Germeshausen L, Tawo Y, Kockler M, Kuhn KU et al (2003). Reduced hippocampal activation during encoding and recognition of words in schizophrenia patients. $A m J$ Psychiatr 160: 1305-1312.

Kaplan RD, Szechtman H, Franco S, Szechtman B, Nahmias C, Garnett ES et al (1993). Three clinical syndromes of schizophrenia in untreated subjects: relation to brain glucose activity measured by positron emission tomography (PET). Schizophr Res 11: 47-54.

Kawasaki Y, Maeda Y, Sakai N, Higashima M, Yamaguchi N, Koshino Y et al (1996). Regional cerebral blood flow in patients with schizophrenia: relevance to symptom structures. Psychiatry Res 67: 49-58.

Kircher TT, Liddle PF, Brammer MJ, Williams SC, Murray RM, McGuire PK (2001). Neural correlates of formal thought disorder in schizophrenia: preliminary findings from a functional magnetic resonance imaging study 3. Arch Gen Psychiatr 58: 769-774.

Kirkpatrick B, Buchanan RW, McKenney PD, Alphs LD, Carpenter Jr WT (1989). The schedule for the deficit syndrome: an instrument for research in schizophrenia 3. Psychiatr Res 30: 119-123.

Klemm E, Danos P, Grünwald F, Kasper S, Möller HJ, Biersack H (1996). Temporal lobe dysfunction and correlation of regional cerebral blood flow abnormalities with psychopathology in schizophrenia and major depression - a study with single photon emission computed tomography. Psychiatr Res 68: 1-10.

Kopp B, Rist F (1999). An event-related brain potential substrate of disturbed response monitoring in paranoid schizophrenic patients. J Abnorm Psychol 108: 337-346.

Lahti AC, Chen LW, Warfel D, Michaelidis T, Bartko JJ, Tamminga CA (1998). The factor structure for psychotic symptoms in inpatients with schizophrenia over three clinical states. Schizophr Res 29: 31.

Lahti AC, Holcomb HH, Gao XM, Tamminga CA (1999). NMDAsensitive glutamate antagonism: a human model for psychosis. Neuropsychoparmacology 21: 158-169.

Lahti AC, Holcomb HH, Medoff DR, Tamminga CA (1995). Ketamine activates psychosis and alters limbic blood flow in schizophrenia. NeuroReport 6: 869-872.
Lahti AC, Holcomb HH, Medoff DR, Weiler MA, Tamminga CA, Carpenter Jr WT (2001). Abnormal patterns of regional cerebral blood flow in schizophrenia with primary negative symptoms during an effortful auditory recognition task. Am J Psychiatr 158: 1797-1808.

Lahti AC, Holcomb HH, Weiler MA, Medoff DR, Frey KN, Hardin $\mathrm{M}$ et al (2004). Clozapine but not haloperidol re-establishes normal task-activated rCBF patterns in schizophrenia within the anterior cingulate cortex. Neuropsychopharmacology 29: $171-178$

Lahti AC, Holcomb HH, Weiler MA, Medoff DR, Tamminga CA (2003). Functional effects of antipsychotic drugs: comparing clozapine with haloperidol. Biol Psychiatry 53: 601-608.

Lennox BR, Park SB, Jones PB, Morris PG, Park G (1999). Spatial and temporal mapping of neural activity associated with auditory hallucinations. Lancet 353: 644.

Liddle PF, Friston KJ, Frith CD, Hirsch SR, Jones T, Frackowiak RS (1992). Patterns of cerebral blood flow in schizophrenia. $\mathrm{Br} J$ Psychiatr 160: 179-186.

Mathalon DH, Fedor M, Faustman WO, Gray M, Askari N, Ford JM (2002). Response-monitoring dysfunction in schizophrenia: an event-related brain potential study. J Abnorm Psychol 111: $22-41$.

Mayberg HS, Brannan SK, Tekell JL, Silva JA, Mahurin RK, McGinnis S et al (2000). Regional metabolic effects of fluoxetine in major depression: serial changes and relationship to clinical response. Biol Psychiatr 48: 830-843.

McGuire PK, Quested DJ, Spence SA, Murray RM, Frith CD, Liddle PF (1998). Pathophysiology of 'positive' thought disorder in schizophrenia. Br J Pschiatr 173: 231-235.

McGuire PK, Shah GM, Murray RM (1993). Increased blood flow in Broca's area during auditory hallucinations in schizophrenia. Lancet 342: 703-706.

Medoff DR, Holcomb HH, Lahti AC, Tamminga CA (2001). Probing the human hippocampus using rCBF: contrasts in schizophrenia. Hippocampus 11: 543-550.

Min SK, An SK, Jon DI, Lee JD (1999). Positive and negative symptoms and regional cerebral perfusion in antipsychoticnaive schizophrenic patients: a high-resolution SPECT study. Psychiatr Res 90: 159-168.

Musalek M, Podreka I, Suess E, Nutzinger D, Passweg V, Strobl R et al (1988). Neurophysiological aspects of auditory hallucinations). 99mTc-(HMPAO)-SPECT investigations in patients with auditory hallucinations and normal controls - a preliminary report. Psychopathology 21: 275-280.

Musalek M, Podreka I, Walter H, Suess E, Passweg V, Nutzinger D et al (1989). Regional brain function in hallucinations: a study of regional cerebral blood flow with 99m-Tc-HMPAO-SPECT in patients with auditory hallucinations, tactile hallucinations, and normal controls. Comp Psychiatr 30: 99-108.

Nordahl TE, Kusubov N, Carter C, Salamat S, Cummings AM, O'Shora-Celaya L et al (1996). Temporal lobe metabolic differences in medication-free outpatients with schizophrenia via the PET-600. Neuropsychopharmacology 15: 541-554.

Penfield W, Perot P (1963). The brain's record of auditory and visual experience: a final summary and discussion. Brain 86: 595-696.

Potkin SG, Alva G, Fleming K, Anand R, Keator D, Carreon D et al (2002). A PET study of the pathophysiology of negative symptoms in schizophrenia. Positron emission tomography. Am J Psychiatr 159: 227-237.

Ragland JD, Gur RC, Raz J, Schroeder L, Kohler CG, Smith RJ et al (2001). Effect of schizophrenia on frontotemporal activity during word encoding and recognition: a PET cerebral blood flow study. Am J Psychiatr 158: 1114-1125.

Raichle ME, Martin WR, Hersevitch P, Mintun MA, Markham J (1983). Brain blood flow measured with intravenous $\mathrm{H}_{2}^{15} \mathrm{O}$. Implementation and validation. J Nucl Med 24: 790-798. 
Ranganath C, Yonelinas AP, Cohen MX, Dy CJ, Tom SM, D'Esposito M (2004). Dissociable correlates of recollection and familiarity within the medial temporal lobes. Neuropsychologia 42: $2-13$.

Rolls ET (2000). Hippocampo-cortical and cortico-cortical backprojections. Hippocampus 10: 380-388.

Sabri O, Erkwoh R, Schreckenberger M, Cremerius U, Schulz G, Dickmann C et al (1997). Regional cerebral blood flow and negative/positive symptoms in 24 drug-naive schizophrenics. J Nucl Med 38: 181-188.

Saykin AJ, Gur RC, Gur RE, Mozley PD, Mozley LH, Resnick SM et al (1991). Neuropsychological function in schizophrenia. Selective impairment in memory and learning. Arch Gen Psychiatr 48: 618-624.

Schroder J, Buchsbaum MS, Siegel BV, Geider FJ, Lohr J, Tang C et al (1996). Cerebral metabolic activity correlates of subsyndromes in chronic schizophrenia. Schizophr Res 19: 41-53.

Shenton ME, Dickey CC, Frumin M, McCarley RW (2001). A review of MRI findings in schizophrenia. Schizophr Res 49: $1-52$.

Shergill SS, Brammer MJ, Williams SC, Murray RM, McGuire PK (2000). Mapping auditory hallucinations in schizophrenia using functional magnetic resonance imaging. Arch Gen Psychiatr 57: $1033-1038$

Siegel Jr BV, Buchsbaum MS, Bunney Jr WE, Gottschalk LA, Haier RJ, Lohr JB et al (1993). Cortical-striatal-thalamic circuits and brain glucose metabolic activity in 70 unmedicated male schizophrenic patients. Am J Psychiatr 150: 1325-1336.

Silbersweig DA, Stern E, Frith C, Cahill C, Holmes A, Grootoonk S et al (1995). A functional neuroanatomy of hallucinations in schizophrenia. Nature 378: 176-179.

Suzuki M, Yuasa S, Minabe Y, Murata M, Kurachi M (1993). Left superior temporal blood flow increases in schizophrenic and schizophreniform patients with auditory hallucination: a longitudinal case study using 123I-IMP SPECT. Eur Arch Psychiatr Clin Neurosci 242: 257-261.
Szechtman H, Woody E, Bowers KS, Nahmias C (1998). Where the imaginal appears real: a positron emission tomography study of auditory hallucinations. Proc Natl Acad Sci USA 95: 1956-1960.

Tamminga CA, Thaker GK, Buchanan R, Kirkpatrick B, Alphs LD, Chase TN et al (1992). Limbic system abnormalities identified in schizophrenia using positron emission tomography with fluorodeoxyglucose and neocortical alterations with deficit syndrome. Arch Gen Psychiatr 49: 522-530.

Van Hoesen GW (1982). The parahippocampus gyrus: New observations regarding its cortical connections in the monkey. Trends Neurosci 5: 345-350.

Vogt BA, Finch DM, Olson CR (1992). Functional heterogeneity in cingulate cortex: the anterior executive and posterior evaluative regions. Cereb Cortex 2: 435-443.

Walter H, Podreka I, Steiner M, Suess E, Benda N, Hajji M et al (1990). A contribution to classification of hallucinations. Psychopathology 23: 97-105.

Weiss AP, Heckers S (1999). Neuroimaging of hallucinations: a review of the literature. Psychiatr Res 92: 61-74.

Weiss AP, Schacter DL, Goff DC, Rauch SL, Alpert NM, Fischman $\mathrm{AJ}$ et al (2003). Impaired hippocampal recruitment during normal modulation of memory performance in schizophrenia. Biol Psychiatr 53: 48-55.

Wolkin A, Sanfilipo M, Wolf AP, Angrist B, Brodie JD, Rotrosen J (1992). Negative symptoms and hypofrontality in chronic schizophrenia. Arch Gen Psychiatr 49: 959-965.

Woodruff P, Brammer M, Mellers J, Wright I, Bullmore E, Williams $S$ (1995). Auditory hallucinations and perception of external speech. Lancet 346: 1035.

Yuasa S, Kurachi M, Suzuki M, Kadono Y, Matsui M, Saitoh O et al (1995). Clinical symptoms and regional cerebral blood flow in schizophrenia. Eur Arch Psychiatr Clin Neurosci 246: 7-12.

Zorrilla LT, Jeste DV, Brown GG (2002). Functional MRI and novel picture-learning among older patients with chronic schizophrenia: abnormal correlations between recognition memory and medial temporal brain response. Am J Geriatr Psychiatr 10: 52-61. 